\title{
Viajes de la música a través de la traducción
}

\author{
Lisa Rose Bradford ${ }^{\bullet}$ \\ Universidad Nacional de Mar del Plata
}

\section{Resumen}

La traducción cantable de letras musicales promueve un rico intercambio cultural y, a su vez, exige una creatividad especial. Aunque hay numerosos elementos que hay que considerar para lograr una versión exitosa, para lo cual, según los estudiosos, hay que buscar una domesticación fiel a la semántica y una equivalencia cantable. Sin embargo, una traducción generativa (Bradford, 2013) puede provocar mayor crecimiento y placer. Se ofrecen dos ejemplos: uno de la música brasileña y otro de las Com/posiciones de Juan Gelman.

\section{Palabras clave}

- Traducción generativa · Traducción cantable · Com/posición · Juan Gelman

\begin{abstract}
Singable translations of lyrics can lead to rich cultural exchanges and, at the same time, demand a special creativity. Although there are numerous elements to consider to achieve a successful version, many critics believe that one must find a domestication faithful to the semantics of the song and thus a singable equivalence. Nevertheless, a generative translation (Bradford, 2013) may provoke greater growth of the original expression and infinite pleasure. Two examples will be analyzed: one from Brazilian music and the other from Juan Gelman's Com/posiciones.

\section{Keywords}

- Generative translation - Singable translation - Com/position . Juan Gelman
\end{abstract}

- Poeta, traductora, compositora y ganadera. Enseña Literatura Comparada en la Universidad Nacional de Mar del Plata, Argentina. Ganadora del premio National Translation Award, acaba de publicar su quinta colección bilingüe de la poesía de Juan Gelman, Today/Hoy y se encuentra elaborando una sexta de Carta abierta y Bajo la lluvia ajena. 
Fusión: ¿unión o liquidación? La globalización que fusiona economías y comunicación mundial de los últimos dos siglos se observa claramente en los intercambios culturales — gente, comidas, arte - y cuanto más porosa una región, más evidente la evolución y las adaptaciones de estas manifestaciones. $\mathrm{O}$ sea, la fusión de las culturas, para bien y para mal. El análisis de la transculturación de la música, por ejemplo, dice mucho de la historia de un lugar y, al igual que el teatro, la mayoría de la transmisión y puesta en escena de la música ha sido oral y muy poco preocupada por la autoría de las expresiones. De hecho, los derechos de autor en cuanto a la reedición y la traducción se desarrollan a finales del siglo XIX y, por lo tanto, las «traducciones» eran en gran parte fusiones de autores. Los cuentos de Boccaccio y El romance de la rosa encontraron nueva elaboración en Chaucer, un soneto de Petrarca se volvía soneto renovado y rebrotado de Thomas Wyatt, por citar solo algunos ejemplos, y de esa forma se expandían el idioma y las convenciones retóricas en la trayectoria de la literatura inglesa. Sin embargo, con la priorización romántica de la originalidad y las legislaciones del derecho de autor, la traducción se limitó enormemente a un intento de "fidelidad", especialmente en cuanto a las versiones de la poesía formal. ¿Pero cuál es la definición de la fidelidad? ¿Fiel al sentido de la semántica o del sonido?

Traducir las expresiones escritas según una métrica o rima estricta hoy en día parece exigir una áspera decisión básica: reproducir la estructura para que la traducción sea lírica o elevar la retórica semántica en post de recrear el ingenio del poema. ¿Culturalmente cuál es más importante? Considerando que la rima y la métrica siempre provocan expresiones aleatorias, a veces con direcciones inicialmente no pensadas por el poeta, es natural que las traducciones también tengan brotes fortuitos. Además, si tomamos el caso más extremo de confines formales, el de la lírica cantada, no hay opción. Hay compases estrictos, rimas eufónicas y acentos que determinan el canto. Entonces se vuelve cuestión de compensar y, en realidad, de generar nuevas canciones en adaptaciones creativas.

La recreación del ingenio y la marca personal de los traductores recientemente llevó a la crítica y traductora Fiona Bell a publicar un artículo muy sugestivo, «The Diva Mode of Translation» (2020). Interesante que, aunque no refiere al asunto de la lírica musical, sí pondera el rol de intérprete de los traductores, que la autora compara al de una diva de ópera, cantante que no solo interpreta un papel, sino, en su figura de cantante adorada, hasta sale de su papel dramático por un momento, reconociendo el aplauso que le brindan y tomando así la forma de la cantante virtuosa. ¿Una traductora diva puede hacer lo mismo?

A través de los siglos, ha habido numerosos comentarios sobre el fracaso de las traducciones cantables, especialmente en las reposiciones de la ópera y, últimamente, en las versiones de obras musicales en el cine ${ }^{1}$. La preocupación por la calidad y los modos de traducir los libretos musicales ha promovido la realización de artículos, sitios de internet y congresos para discutir el tema, ponderando las técnicas y criterios a tener en cuenta, desde el énfasis que provee el ritmo hasta la formación de las vocales que con ciertos tonos son agradables o, por el contrario, imposibles para los cantantes. 
Sin embargo, las traducciones cantables de otros géneros de canciones, si bien tienen los mismos elementos, como no forman parte de una narrativa dramática, no exigen la misma adherencia a la semántica que las obras de ópera. De hecho, esas traducciones muchas veces configuran adaptaciones o "traducciones generativas» (Bradford 2013, 2016, 2017) de una canción.

Algunos de los estudios sobre las traducciones cantables comienzan repasando las teorías de John Dryden y Friedrich Schleiermacher para anclar una terminología y definir el propósito de la traducción. Poeta y traductor, Dryden propone en su ensayo "From the Preface to Ovid's Epistles» un modelo de tres modalidades: metáfrasis, una versión palabra por palabra, en teoría «fiel» a la semántica, aunque no ofrece las constelaciones de impacto de una palabra; paráfrasis, una especie de interpretación más allá de la semántica; e imitación, una recreación que da libertad a los traductores para generar una versión según su apreciación estética de la obra. Las demarcaciones entre las tres modalidades son sumamente fluidas, pero ayudan a entender los procedimientos y el «énfasis», utilizando la palabra de Borges ${ }^{2}$, o las prioridades de los escritores traductores.

Schleiermacher, muy citado entre traductores en las últimas décadas, principalmente por su resucitación por Antoine Berman y Lawrence Venuti, fue teólogo y filólogo del romanticismo alemán, y su importancia radica en su promoción de una traducción que llevara a los lectores a los autores originales a través de su cultura y su idioma con la intención de expandir la lengua de llegada en lugar de domesticar, limitar y así violentar o conquistar la obra fuente. Su sistema de clasificación se basa en el contraste entre interpretación y traducción: la primera es una cuestión muchas veces oral que se maneja en el mundo comercial, mientras la segunda es escrita y pertenece al mundo del arte y las ciencias. Más allá de esta diferencia, utiliza las nociones de paráfrasis e imitación, alegando que la primera representa una reducción de la obra y la segunda una recreación de impresión. Sin embargo, luego agrega a la segunda noción: la de la transparencia, un concepto que ha reinado en la mayoría de las traducciones a través del tiempo y promueve el propósito de que no se note que el texto escrito sea una traducción, que se lea como si fuera una obra redactada en el idioma de llegada directamente, lo cual implica la domesticación del texto y una limitación en cuanto a la introducción de expresiones extrañamente novedosas.

Volviendo a Berman y Venuti, los títulos mismos de sus libros más impactantes - La prueba de lo ajeno y La invisibilidad del traductor - apuntan a la alegría de disfrutar de lo peregrino de una obra extranjera y de la creatividad ingeniosa o la marca personal del escritor/traductor, una marca «diva».

Ahora, ¿cómo se aplican estas nociones básicas a la traducción de un texto musical? Otra vez, obedece al propósito: usando la terminología de Schleiermacher, depende si es para interpretar el sentido o traducir su efecto, interpretación versus imitación. En el caso de glosas o subtítulos, los dos extremos pueden encontrar un punto medio, pero para crear una traducción cantable, hay tantos elementos para tomar en cuenta que ese acto parece imposible.

En primer lugar y como apreciación básica de la traducción literaria, cada idioma, como los instrumentos de una orquesta, suena distinto. Algunos pueden sonar como violines y otros como oboes. Las consonantes pueden parecer ásperas o silbantes y las vocales pueden ser muy abiertas o muy cerradas; en los dos casos 
cambia la manera de vocalizar, haciéndolo más o menos fácil para el cantante; concordando o no con el significado. También los ritmos son fundamentales para la música: algunos según las sílabas y otros, el acento. O sea, los distintos idiomas son inconmensurables: las equivalencias son imposibles y entonces las imitaciones son inventos personales y en gran parte aleatorios.

Volviendo al elemento narrativo, en la ópera o las obras musicales, especialmente las dirigidas al público más joven como las populares animaciones de Disney, según la mayoría de los estudiosos, es esencial domesticar las versiones para no perder el hilo dramático. Juegos de palabras que se ganan, juegos que se pierden; eufonías, lo mismo. Dos publicaciones muy ilustrativas y didácticas que se dirigen a estos textos y brindan estudios de casos concretos se encuentran en el excelente libro Translating for Singing (Apter y Herman, 2016) y el artículo «Breaking Free of the Language Barrier in Music» (Bontrager, 2016/18). En ambos análisis, se comentan y comparan cuestiones de la rima, el ritmo y la ubicación de las palabras importantes de las «crestas» del compás.

En el estudio de Bontrager, se enfocan casos de la música contemporánea, en particular las películas musicales de Disney, tomando como ejemplo sus canciones tan populares traducidas al castellano en España y México, mostrando así como algunas adaptaciones cambian el sentido de las canciones y otras son muy torpemente compuestas. Al final, ofrece alternativas de su propia creación que se mantienen «invisibles» en cuanto a la normalidad de las palabras, la sintaxis y las cadencias naturales.

Apter y Herman, que se dedican a la traducción de la música lírica, también ofrecen casos comparativos para estudiar la eufonía de distintos idiomas, el uso de palabras extranjeras, la ventaja de crear repeticiones como herramienta de rima, las convenciones y sensibilidades de distintas culturas y el significado del sonido.

Esta última noción es particularmente importante. Por un lado, hay sonidos alegres y livianos, oscuros o pesados y/u onomatopéyicos, pero traducidos a otro idioma muchos de ellos se alteran. Nos levantan o nos deprimen, nos incitan a bailar o a contemplar nuestra existencia. Por otro lado, en muchas instancias escuchamos una música atrapante sin prestar atención a la letra y/o somos ignorantes de que existiera una versión original en otro idioma o una procedencia de una obra narrativa. Esto comprueba que el sonido tiene tanto o más sentido/significado que la letra. ¿Cuántas canciones se escuchan en las radios de todas partes del mundo que se transmiten en idiomas no comprendidos? ¿Cuánta música religiosa se ha traducido sin pensar después en su origen? ¿Quién puede ubicar la versión «original» de las baladas inglesas, cuando se adaptaban y se transformaban a las necesidades de cada comunidad? ¿Cuántas personas pueden nombrar las obras de las cuales salen las canciones individuales de los Gershwin, Steven Sondheim, Rogers y Hammerstein o Andrew Lloyd Weber? ¿Podemos disfrutar de una famosa aria sin entender su fuerza semántica y narrativa? En fin, ¿̨tiene importancia la ignorancia si es la melodía lo que nos conmueve?

Quisiera repasar algunas instancias de estas traducciones musicales del ámbito personal para examinar e ilustrar este fenómeno. Hace un par de años una amiga me pidió que cantara con ella la versión brasileña de la canción «Like a lover», canción que se hizo muy famosa por Sergio Mendes en los años 60 en inglés y que docenas de cantantes en los EEUU han grabado desde entonces. Cuando me fijé en la letra de la canción original «O cantador» (Dori Caymmi / Nelson 
Motta), me di cuenta de que esta letra seguía la tradición de un triste fado, del sufrimiento del amor que lleva al cantante a la desesperación, mientras la versión de los célebres liricistas Marilyn y Alan Bergman en inglés surge de Shakespeare en su alegre voyerismo y erotismo:

\author{
Amanhece, preciso ir \\ meu caminho é sem volta e sem ninguém \\ Eu vou prá onde a estrada levar \\ Cantador só sei cantar \\ Ah! eu canto a dor \\ canto a vida e a morte, canto o amor
}

Like a lover the morning sun

Slowly rises and kisses you awake

Your smile is soft and drowsy as you let it play upon your face

Oh how I dream I might be like the morning sun to you

Dentro de una tradición de aubade, pero de maneras sumamente diferentes, en el original el cantor canta dolor; en la versión en inglés, al deseo de imaginarse tocando al amante: "Oh that I were the glove upon that hand» diría Shakespeare en Romeo y Julieta. En realidad, la popularidad de la melodía en Brasil y en EEUU lleva la canción a un goce universal que va más allá de las letras. Entonces, parecería que la traducción de música sigue más una convención de traducción generativa que traducción tradicional y promueve el crecimiento de una manifestación gracias a la adaptación. O sea, una traducción de modo diva. Como desarrollé en un artículo publicado en este medio en el año 2017 para definir mi denominación:

Las distintas translaciones no pueden sino agregar al original y de esta manera revivir la fuente y hacer que se propague. Como arqueólogos y curadores de las creaciones escritas, los traductores des/cubrimos, cultivamos y negociamos palabras para así generar nuevas obras. Muchas de estos rebrotes, a través de la traducción generativa (Bradford, 2013), se vuelven manantiales para nuevas creaciones, las que funcionan para revelar y resucitar la articulación original como continuación del efecto seminal, aunque crecen de manera diferente. Este modo de versionar inclusive refleja el genio del autor original y del autor traductor (Bradford, 2017).

La poesía misma de los siglos XX y XXI ha tendido más y más a una suerte de imitación (Robert Lowell) de metapoemas (Holmes), transcreaciones (Haroldo de Campo) o de palimtextos de absoluta apropiación de com/posición ${ }^{3}$ (Juan Gelman). Del poeta argentino surgen muchos ejemplos de sus Com/posiciones (2013). Es más que lógico que la música siga un camino parecido.

Un ejemplo del citado libro brindará más elementos para ponderar y entender estos procedimientos traductores, reviendo un poema que analicé en aquel artículo y comentando su consiguiente musicalización. Hay un poema de esta colección que Gelman escribe en base a un poema hebreo del siglo X: 


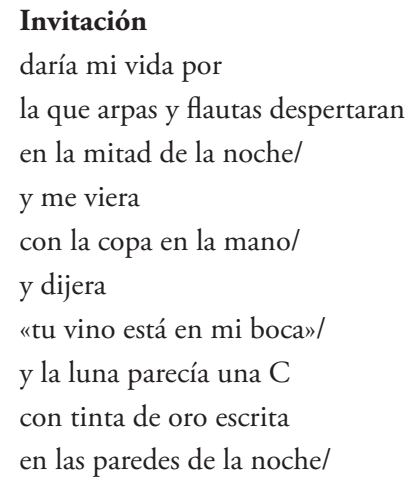

Este poema de Samuel Hanagid (Samuel el Nagid o Príncipe) refleja las tertulias medievales de los emiratos en su reino de Andalucía entre los siglos VIII al XV. Representa imágenes de la música, la naturaleza y los atractivos sirvientes. La versión más literal en prosa de Carmi que se encuentra en The Penguin Book of Hebrew Verse (1981) una fuente frecuente para Gelman:

I would lay down my life for the fawn who, rising at night to the sound of melodious harp and flute, saw a cup in my hand and said: "Drink your grape's blood from between my lips». And the moon was like a C inscribed in golden ink upon the robes of night (1981:298).

(Daría la vida por la cierva que, levantándose a la noche al sonido melodioso de arpa y flauta, vio una copa en mi mano y dijo, «Beba la sangre de su uva de mis labios». Y la luna parecía una $\mathrm{C}$ escrita con tinta dorada sobre el manto de la noche. Mi traducción). ${ }^{4}$

Gelman amasa las palabras para producir algo fresco y novedoso. Con su estilo despojado, omite el tropo de la «sangre de la uva» y deja del lado la figura del ciervo - macho o hembra - y enfatiza el erotismo del concepto «tu vino está en mi boca». Evocada por la memoria o el deseo en vez del poema original o la realidad — con frecuencia los sirvientes eran muchachos jóvenes vestidos de manera seductora - esta figura invita al lector a acompañar al poeta en su ensueño.

Gelman estuvo en Buenos Aires en agosto del 2013 para el lanzamiento de su último libro, Hoy.

Nos encontramos en un departamento en Barrio Norte que le prestaron para hablar de la traducción de este nuevo libro, pero terminamos hablando de caballos y de mis poemas y, también, de su enfermedad. Antes de viajar de México, le habían hecho dos transfusiones y se lo veía muy frágil. Unas semanas antes de su muerte, decidí crear una canción de mi versión en inglés fusionada con esta com/posición para mandarle como regalo de fin de año. Elegí este poema porque se presta a una analogía de la relación entre la traducción y escritura «original», de cómo una traductora toma las palabras de un poeta. Por cuestiones de ritmo y «crestas» de las palabras importantes, una vez establecida la melodía, tuve que editar mi versión en inglés:

Oh I would give my life for one

wakened by harps and flutes

in these small hours /

to find me here / 
glass in hand /

and say

"your wine is in my mouth» /

the moon like a $\mathrm{C}$

in golden ink

painted on walls of night /

yes, I would give my life for this /

Your wine is in my mouth.

Se la mandé a los apurones (murió a los catorce días), pero dos años más tarde retomé la pequeña melodía para crear una verdadera canción, una especie de homenaje a Gelman, agregando la versión del libro Com/posiciones en castellano. Como siempre ocurre en la adaptación de un texto a una música preestablecida, también tuve que retocar su expresión y el texto mismo hizo crecer un nuevo brote por una rima natural que surgió de la versificación, que no admitía las dos sílabas de la palabra «boca» aunque parecía ser fundamental para el concepto original del poema de Samuel Hanagid. Sin embargo, en mi mente escuché «sed», una rima con la palabra "pared»:

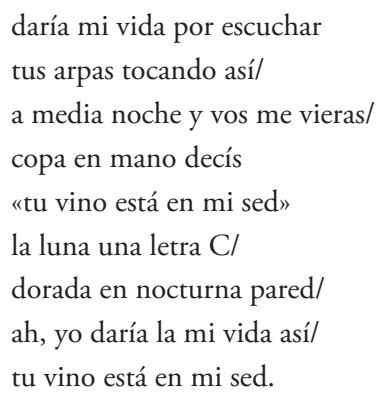

Confieso que la noción, que salió de forma aleatoria, me fascinaba y, por lo tanto, cantando la estrofa por segunda vez en inglés, también cambié el verso, «your wine is in my thirst». El tropo se transformó de "tu vino está en mi boca» en "tu vino está en mi sed», pero sin perder el erotismo; de hecho, lo expandió como si fuera una contestación al primer concepto, más complejo y evocativo.

¿Herejía o resurrección y reencarnación de un poema antiguo? A quienes la han escuchado, siempre con mi prefacio explicativo, les ha encantado, lo cual demuestra que la traducción generativa en la música no traiciona al poema original sino que promueve el disfrute de los intercambios culturales. Así una tradición de fado en la bossanova se vuelve música tropical con ingenios shakespeareanos o un poema hebreo del siglo X toma la tradición fluida de la balada inglesa. De manera parecida, es lógico que un aria sea casi incomprensible en cualquier idioma, incluyendo el original, y todo esto demuestra que el poder principal de la retransmisión de los fenómenos musicales está en la gracia de la melodía y la interpretación vocal. Esto no significa que no sigamos traduciendo las letras musicales por ser superfluas en la performance, sino que entendamos que la traducción es una oportunidad de crecimiento cultural a pesar de y gracias a los cambios que se imponen al texto.

Aquí es preciso reiterar nociones de mi planteo respecto de la traducción generativa: se podría considerar toda composición como versión de obras anteriores y 
futuras, que funciona en una zona cognitiva de descubrimiento y crecimiento. La traducción de la música ofrece una especie de sinestesia, dejándonos ver un mundo a través de dos lentes, palabras fusionadas por la sonoridad. Muchos autores tienden a crear efectos sensoriales orgánicos en sus textos y los traductores debemos crear instrumentos innovadores de onomatopeya, eufonía o disonancia, acordes y/o rimas para seducir a través de un "transformance» para los lectores/espectadores/oyentes nuevos. Toque y fuga y adoramos a la «diva». De este modo se entiende cómo las poéticas de un deseo hacia un sirviente se transforman en un sorbo de vino y el vino de un canto pasa de una boca a otra creando una trova totalmente nueva que, a su vez, sigue dando sed de otro sorbo: transformaciones que entretejen hilos de rapsodias para cada nuevo receptor, nuevo traductor, nuevo compositor. $\mathrm{O}$, como parece que dijo alguna vez Robert Schumann: «Para componer lo único que hay que hacer es acordarse de una melodía que nadie antes ha pensado». Una fusión de memoria pasada, presente y futura en el sabroso viaje de la música.

\footnotetext{
Notas

${ }^{1}$ Un proyecto internacional, «Translating Music», se inició en 2013 entre universidades inglesas e italianas; también existe la «Lyrica Society for Word-Music Relations» (http://www.lyricasociety.org/), para nombrar algunos foros.

${ }^{2}$ Borges escribió varios ensayos sobre este tema, abarcando la lectura, la composición y la traducción. En su célebre texto, «Las versiones homéricas» dice que la traducción ofrece «diversas perspectivas de un hecho móvil, [...] un largo sorteo experimental de omisiones y de énfasis» (1975:239). O sea, parecido a lo que han escrito Gelman y Marías sobre el traslado lingüístico de la literatura, es cuestión de una recreación de la memoria del traductor. También comentó en «La busca de Averroes»: «[...] el tiempo, que despoja los alcázares, enriquece los versos» (1975:586-7), alegando que las grandes imágenes son cuestión no de maravilla instantánea sino de lenta expansión.

${ }^{3}$ En su «Exergo» escrito en 1984, Gelman explica, «llamo com/posiciones a los poemas que siguen porque los he com/puesto, es decir, puse cosas de mí en los textos que grandes poetas escribieron hace siglos. Está claro que no pretendí mejorarlos. Me sacudió su visión exiliar y agregué —o cambié, caminé, ofrecí- aquello que yo mismo sentía. ¿Cómo contemporaneidad y compañía? ¿mía con ellos? ¿al revés? ¿habitantes de la misma condición?» (Gelman, 2013:4).

${ }^{4}$ Raymond Sheindlin amolda los mismos versos para aumentar su musicalidad de esta manera: «How exquisite that fawn who woke at night / To the sound of viol's thrum and tabor's clink, / Who saw the goblet in my hand and said, / "The grape's blood flows for you between my lips. / Come drink". / Behind him stood the moon, a letter C, / Inscribed on morning's veil in golden ink» (1986:69).
} 


\section{Referencias bibliográficas}

Apter, R. y Herman, M. (2016). Translating for Singing. Bloomsbury. Bell, F. (2020). The Diva Mode of Translation. Asymptote Journal. https://www.asymptotejournal.com/nonfiction/fiona-bell-the-divamode-of-translation/

Bontrager, G. (2011). Breaking free of the Language Barrier in Music. URL:http://translationjournal.net/journal/57lyrics.htm.

Borges, J.L. (1975). Obra completa. Emecé.

BradFord, L.R. (2013). «Generative Translation» in Spicer, Gelman and Hawkey. CLCWeb, 15.6 http://docs.lib.purdue.edu/clcweb/.

BRADFORD, L.R. (2016). Haunted Compositions: Ventrakl and the Growth of George Trakl. Translation Review, (95:1) 41-54.

Bradford, L.R. (2017). Tu vino está en mi boca. El taco en la brea (5). https://bibliotecavirtual.unl.edu.ar/ojs/index.php/ElTacoenlaBrea/ issue/view/622.

Carmi, T. (1981). The Penguin Book of Hebrew Verse. Penguin.

Davidson, M. (1988). Palimtexts: Postmodern Poetry and the Material Text. En Perloff, M. Postmodern Genres. U. Oklahoma Press.

Gelman, J. (2013). Com/positions. [Traducción Lisa Rose Bradford]. Coimbra Editions.

Holmes, J. (1988). Translated! Papers on Literary Translation and Translation Studies. Rodopi.

Marías, J. (2001). Literatura y fantasma. Alfaguara.

Perteghella, M. y Loffredo, E. (2006). Translation and Creativity: Perspectives on Creative Writing and Translation Studies. Bloomsbury. Scheinduin, R. (1986). Wine, Women, and Death. Jewish Publication Society. 